\title{
EL ANÁLISIS TRANSACCIONAL COMO HERRAMIENTA PARA GUIONISTAS DE CINE Y TELEVISIÓN
}

\author{
Graciela Padilla Castillo ${ }^{1}$ \\ Universidad Complutense de Madrid. Departamento de Periodismo III, Madrid, \\ España.
}

\section{RESUMEN}

La presente investigación analiza la potencialidad del Análisis Transaccional como herramienta para guionistas de cine y de televisión. La primera parte profundiza en algunas obras de guionistas que citan el Análisis Transaccional, de Eric Berne, y otras teorías para conseguir la inspiración y un buen guion. La segunda parte concentra las principales partes del Análisis Transaccional y su aplicación en la película Babel (2006), dirigida por el mexicano Alejandro González Iñárritu.

\section{PALABRAS CLAVE: Guion, Análisis Transaccional, Eric Berne, Alejandro González Iñárritu, Babel, Transacciones, Juegos Psicológicos.}

\section{ABSTRACT}

This research analyzes the potential of Transactional Analysis as a tool for film and television writers. The first part delves into some works of writers who cite Transactional Analysis, Eric Berne, and other theories to get inspiration and a good script. The second part concentrates the main parts of the Transactional Analysis and its application in the movie Babel (2006), directed by the Mexican Alejandro González Iñárritu.

KEY WORDS: Script, Transactional Analysis, Eric Berne, Alejandro González Iñárritu, Babel, Transactions, Psychological Games

Graciela Padilla Castillo. (2011) EL ANÁLISIS TRANSACCIONAL COMO HERRAMIENTA PARA GUIONISTAS DE CINE Y TELEVISIÓN. Revista de Ciencias de la Comunicación e Información. (Diciembre 2011). Año XXV (28), 42-60 ISSN: $\quad$ 0213-070-X Recuperado: http://www.revistaccinformacion.net/ARTICULOS/2011\%20Paula\%20Requeijo/2011.\%20 El\%20an\%C3\%A1lisis\%20transaccional.\%20Graciela\%20Padilla.pdf

\section{INTRODUCCIÓN}

\footnotetext{
${ }^{1}$ Graciela Padilla Castillo: Profesora de la Facultad de Ciencias de la Información, Universidad Complutense de Madrid. Acreditada a Profesora Titular. Doctora en Ciencias de la Información con Premio Extraordinario de Doctorado, y Licenciada en Periodismo y Comunicación Audiovisual con Premio Fin de Carrera. Ha completado su formación posdoctoral en la Universidad de California en Los Ángeles (UCLA) y ha viajado como experta en estudios de género, a la Benemérita Universidad Autónoma de Puebla (BUAP, México). Sus líneas de investigación se centran en Ficción televisiva, Teoría de la Información, Ética y Deontología y Comunicación Política. Es autora y coautora de casi un centenar de publicaciones: libros, capítulos de libro y artículos académicos, publicados en revistas de impacto. Asimismo, ha participado en más de una treintena de investigaciones con subvenciones competitivas y proyectos de innovación docente.
} 
María Teresa Forero, guionista y escritora, explica en uno de sus libros que sus fuentes de inspiración son varias. Nos interesan las dos más importantes: el Análisis Transaccional y las noticias de sucesos. Esta autora manifiesta que la inspiración del guionista no proviene de la inspiración divina ni de la casualidad, sino de la búsqueda de noticias, de personas reales y del análisis y reconstrucción de los sucesos que les ocurren y de sus personalidades.

Proponemos aquí seguir la estela de Forero y proponer una nueva vía para el Análisis Transaccional (AT) como herramienta valiosa y potente para la creación de personajes. Analizaremos los libros y manuales de los principales guionistas españoles y norteamericanos, sus consejos y sus herramientas tomadas del AT y de la Psicología, y los pasos para crear un guión y todos sus personajes.

El análisis de la literatura académica de este campo sirve para corroborar la idea de Forero en el tiempo. Por ejemplo, la Biblia televisiva de una serie, el manual de los guionistas que cuenta el pasado y las intimidades de los protagonistas de cada serie, no es otra cosa que un gran manual transaccionalista porque desvela la personalidad del protagonista y qué le ha llevado ahí. Esas biblias contienen sus estados del ego, sus transacciones y juegos favoritos, su guión de vida; en definitiva, el arco completo del personaje, desde su creación virtual hasta más allá de su muerte o de la cancelación de la serie.

Los ejemplos también pueden tomarse del cine, donde guionistas y directores de varias épocas han recurrido a la figura del psicólogo para mostrarlo en sus películas y hablarnos del interior de sus personajes. Podemos recordar los psicólogos del cine, los que bien pueden ser considerados transaccionalistas y concretamente, el caso de la filmografía de Woody Allen, director especializado y obsesionado con lo psicológico. Sin embargo, el final de la investigación se aplicará al caso concreto de la película Babel (2006), de Alejandro González Iñárritu.

\section{ESCRIBIR PARA CINE Y PARA TELEVISIÓN: TRABAJO EN LUGAR DE INSPIRACIÓN}

"Pocas cosas hay más fascinantes que crear un personaje" (Forero, 2002: 81). Así comienza María Teresa Forero uno de los capítulos de su libro Escribir televisión. Manual para guionistas. Esta frase es citada, de distintas formas, en cualquier libro de guionistas. Antes de cualquier consejo, de cualquier estrategia, todos coinciden en que lo más bello es dar vida, credibilidad y evolución a los personajes.

Nash y Oakey (1978: 7) hablan de hacer que los personajes sean "humanos". El espectador tiene que ver cómo actúan y cómo sus acciones tienen consecuencias, como en la vida real. En el guión tiene que haber personajes que parezcan personas, porque las historias versan sobre personas y al mismo tiempo, se dirigen a ellas. Por eso, Kelsey (2003: 177) dice que no importa tanto sobre qué escribes, sino sobre quién escribes. $Y$ saber quiénes son nuestros personajes no es sólo darles nombres y describir su apariencia (Kelsey, 2003: 177). Al mismo tiempo, Sussman (1995: 166) añade que el bloqueo de las historias de ficción se evita dando 
acción al argumento y a los personajes. No hay que dar explicaciones, sino diálogo y avance al guion.

Todas las ideas anteriores no son modernas, sino clásicas. Aristóteles, en su Poética, ya dijo que los personajes o caracteres son los culpables del desarrollo del drama. Añadía que, según el tipo de obra, se daría mayor o menor profundidad a los personajes. En cualquier caso, ellos son el componente principal y la base del éxito de la historia. El espectador debe saber cómo opinan y por qué actúan como actúan en la obra (Forero, 2002: 82).

Ese porqué tiene su esencia en el pasado y en el futuro de los caracteres. Dado el corto tiempo que dura una película o un capítulo de serie, no hay tiempo ni espacio "para demorarse en la historia de cada personaje, como sí se puede hacer en la novela" (Kelsey, 2003: 177-178). Sin embargo, hay posibilidades y opciones para esbozarlos y explicarlos. Se pueden dar detalles, conductas, pistas, especialmente si se trata de una serie de televisión. ¿Cómo? A través de lo que dicen y hacen, como ya hemos señalado anteriormente.

El problema es inventar varios personajes, dar profundidad a todo el reparto, atender los encargos de las productoras y hacerlo bien. La inspiración no es eterna, ni casual; sino que es fruto del trabajo. Por eso, el guionista debe leer e informarse. Muchos reconocen que se inspiran en las noticias de sucesos. CSI Las Vegas nació de un periódico de la misma ciudad. Su creador trabajaba en un hotel, aparcando coches de huéspedes ricos. Al llegar a su casa, cada tarde, leía los misterios y crímenes sin resolver de una pequeña columna del diario. Vio material para una serie. Vendió la idea y se hizo más rico que los dueños de aquellos coches que conducía.

A David Shore, creador de House, le ocurrió algo parecido. Era abogado pero leía casos médicos extraños en la columna de otro periódico americano. Esos casos conformaron las tramas de la primera temporada de su serie. Los dos ejemplos muestran que la inspiración puede proceder de la misma realidad.

En el caso de las tv movies, o películas para televisión, esta idea es aún más palpable. El género vive, en la actualidad, un renacer en nuestro país y se basa en historias reales, en noticias que conmovieron al público. Desde la historia de siete adolescentes que se quedan embarazadas, al mismo tiempo, para cubrir a una de ellas (El pacto); hasta otra historia de dos adolescentes que son secuestradas y sufren un fuerte síndrome de Estocolmo tras su liberación (El secuestro). ¿Perjudica esa inspiración real a la tv movie o la serie? En absoluto. De hecho, parte con ventaja; si la noticia acaparó la atención del público, la ficción volverá a conseguirlo aprovechando una especie de audiencia de arrastre.

No obstante, algunos guionistas huyen de ese componente tan realista y dicen basarse en su imaginación y en la mezcla de personas y tipos que conocen. Pueden partir de una anécdota, de una frase, de una broma o de una situación, para dar vida a un héroe o a un anti-héroe; protagonista en cualquier caso. Es el comienzo para trazar la psicología y el interior del personaje. La fuente para ahondar en esa 
profundidad está en la Psicología. Igual que ayuda a conocer a las personas, ayuda a conocer a personajes y en este caso, a crearlos.

Algunos guionistas hablan de Freud, otros de Jung, otros se proclaman fans del conductismo. Sin salir de los guionistas españoles, María Teresa Forero recomienda el Análisis Transaccional de Eric Berne y sus guiones de vida. Argumenta que todos estamos "programados para ser cierta manera" (Forero, 2002: 86). Esa misma programación se puede usar para crear, desde cero, a un personaje. No se carecerá entonces de ese calado psicológico que busca el guionista.

La autora introduce la teoría que aquí nos ocupa y nos interesa. Divide los guiones entre culturales, subculturales e individuales. Esboza el esquema de personalidad y los Estados del Ego: Padre, Adulto y Niño. Y sentencia: "Podemos valernos del análisis transaccional preguntándonos, cuando escribimos un guion, en qué estado del ego se hallan los personajes de cada escena" (Forero, 2002: 87).

Imaginamos una situación, ponemos un personaje contra otro, le damos a cada uno un estado y los variamos, pensando en las distintas respuestas. La fuente de inspiración para un diálogo, y para toda una trama, resulta así inagotable. Por ello, afirmamos que el guionista trabaja, ensaya y experimenta. Desarrolla su oficio y no se queda en la inspiración. Sería ególatra y quimérico decir que todo proviene de la simple iluminación.

\section{EL COMIENZO DE UN GUIÓN}

Conociendo ya las posibilidades que nos brinda el Análisis Transaccional, deseamos introducirnos en la creación de una película o de una serie. Todos los guionistas coinciden en que hay que empezar con una biblia, un manual, un pequeño libro, que defina a todos los personajes y nos hable de sus pasados. Es una especie de libro de estilo, que enumera todos los personajes, con sus características físicas, personales y biográficas.

Además, todo el equipo de guionistas puede acudir a ella en el futuro para no incurrir en errores o contradicciones. López añade que contiene lo que se pretende hacer en la película 0 en la serie y que es una especie de declaración de intenciones que explica los motivos y las razones del posible éxito (López, 2008: 38).

Es aquí donde entra en juego el Análisis Transaccional y los consejos de María Teresa Forero. Si queremos dar profundidad psicológica nuestros personajes y hacer una biblia sólida, podemos recurrir a los guiones de vida. Tenemos un personaje y varios secundarios que le acompañan. Poseemos un conflicto, una otredad, un hecho que le desborda y cambia de repente su existencia. Sabemos cómo seguirá hacia delante y cómo será su arco de personaje. Aunque dónde va no importa nada si no sabemos de dónde viene y cómo ha llegado hasta el comienzo de la historia que queremos contar.

Por esta razón, contamos con una herramienta valiosísima en la teoría de los guiones de vida que creó Eric Berne. Gracias a ellos, damos pasado a los personajes, les concedemos una vida anterior y unas razones para avanzar. 
Simplemente, tomando cada uno de esos guiones y acercándolos a cada protagonista, encontraremos inspiración para crea un reparto coral en condiciones.

Cuando se tiene una biblia más o menos esbozada, se procede a la venta de la idea. Si esa idea es adquirida por una productora, de cine o de televisión, se procede al rodaje. En el caso de la pequeña pantalla, el rodaje se reduce a una primera oportunidad: el episodio piloto, que procura atraer al público desde el principio. Cantor (1981: 72) lo define como una forma perfecta para la búsqueda de nuevas series. Asimismo, recuerda que muchos pilotos han acabado en la gran pantalla por su calidad y posibilidades de explotación. En otras ocasiones, si la idea de la serie no es vendida, el piloto se convierte en TV movie y es emitida por televisión como cualquier otra película.

Todas estas opciones llevan a la pregunta de por qué puede fallar un episodio piloto. Los grandes expertos explican que a veces falta una intención. El director de cine Sidney Lumet (2004: 39) comparte esta idea y explica que nunca pide algo al guionista en su primer encuentro. Sólo quiere que responda a unas preguntas: ¿De qué trata la historia? ¿Qué viste? ¿Cuál era tu intención? Si el guionista sabe responder con seguridad es que tiene una historia que contar. $Y$ si hay historia original, es probable que haya piloto.

Sin embargo, las intenciones no bastan. El resultado de esa idea materializada debe ser un episodio de calidad considerable y tono impactante. Si al espectador no le gusta este primer contacto, no seguirá los episodios siguientes. Por ello, todo piloto arranca con un hecho efectista a modo de terremoto televisivo. Lumet (2004: 41) decía: "El guion debe romperte el saque, sorprenderte, entretenerte, involucrarte y, al llevarle al desenlace, dejarte sin embargo con la sensación de que la historia no podía acabar de otra manera".

Natxo López prefiere hablar de "detonante" y de "escaleta", como aquello que detona una historia en general y que hace que la historia comience (López, 2008: 37). Completa que este detonante no tiene que ser siempre drástico y radical, pero suele coincidir con "una variación de situación laboral o vital del protagonista, o con la llegada de un nuevo personaje a un lugar concreto" (López, 2008: 38). Lo cierto es que sirve para arrancar la serie pero muchas veces, deja de tener importancia ya en el segundo episodio. Es la base para seguir adelante. Nuestros personajes tienen ya a dónde ir y sabemos de dónde vienen, gracias a sus guiones de vida que conforman, también, el guion del resto de la trama.

\section{EJEMPLO DE CÓMO SE PUDO APROVECHAR EL ANÁLISIS TRANSACCIONAL PARA ESCRIBIR UN GUIÓN}

A partir de lo enunciado anteriormente, pretendemos transmitir que el Análisis Transaccional es base de creación de guiones y en consecuencia, de análisis de estos. Esta idea es fruto de la investigación y de la lectura de los artículos del Profesor Felicísimo Valbuena (2006b, 2007a, 2007b). Por otro lado, y como suele ocurrir en el Análisis Transaccional, también parte de una experiencia personal. Esta vivencia nos sucedió hace poco y nos hizo plantearnos por qué a las personas que no hemos estudiado Psicología, y venimos de otras disciplinas, nos atrae tanto el 
AT. Prestamos a una amiga periodista las fotocopias del libro ¿Qué dice usted después de decir Hola? Después de leerlas, nos dijo: "¡Esto es la Biblia del ser humano!". Su comentario nos pareció muy acertado. Nos quedamos pensando por qué el AT nos parece una revelación. Creemos que es porque este método dispone de dos características que a menudo parece difícil encontrar juntas: profundidad y fácil comprensión.

La profundidad ya la hemos citado antes porque el AT es una herramienta potente a la hora de analizar la mente humana y la comunicación intrapersonal. También, las relaciones con el otro y los otros (comunicación interpersonal), las relaciones en grupos y en organizaciones. Por otro lado, la fácil comprensión deriva, sin duda, de la vocación social de Eric Berne. Dedicó su vida al trabajo. Deseaba que las personas que no podían afrontar económicamente la psicoterapia consiguieran analizarse a sí mismas, conocerse, entenderse y ayudarse.

Nada más comenzar ¿Qué dice usted después de decir Hola? declara: "Puestos a elegir entre lo arcano y lo abierto, entre la supercomplicación y la simplicidad, me he puesto del lado de "la gente", blandiendo de vez en cuando una palabra pomposa como una especie de hamburguesa para distraer a los perros guardianes de las academias, mientras me introduzco por la puerta del sótano para saludar a mis amigos" (Berne, 2002: 14).

El lenguaje que utiliza se aleja de los tecnicismos y entra de lleno en lo cotidiano, en lo coloquial. Buena prueba de ello son los nombres con los que bautizó a los Juegos: ¿No es Horrible?, Dame una patada, Si no fuera por ti, Policías y Ladrones, ¿Por Qué No? Sí pero.... Rickshaw, etc. Por otro lado, hay un factor que facilita e incluso, hace divertida la lectura de sus textos: el uso del humor. El sistema de Berne, además, nos capacita para entender y poner nombre no sólo a los casos extremos, sino también a los fenómenos habituales.

Para ejemplificar la utilidad del AT en nuestro campo, el de la comunicación, hemos seleccionado Babel (2006), una película del director mexicano Alejandro González Iñárritu. Creemos que su director y sus guionistas se basaron en la Psicología y bien podrían haberse centrado en el Análisis Transaccional, como se muestra en las líneas siguientes.

\section{ESTADOS DEL EGO}

Los personajes de Babel poseen distintos estados, ya que tienen vidas diferentes en países dispares. Sus tragedias les han hecho reaccionar de forma heterogénea y se pueden encontrar todos los yo que definió Berne: "Los estados del yo son fenómenos fisiológicos normales. El cerebro humano es el órgano u organizador de la vida psíquica, y sus productos se organizan y almacenan bajo la forma de estados del yo" (Berne, 2002: 33).

NIÑO: Berne dijo que "en el Niño residen la intuición, la creatividad, el impulso y el disfrute espontáneos" (Berne, 2002: 33). El personaje de Santiago, sobrino de Amelia, reúne estas características. Es un adulto pero, como se ha indicado 
anteriormente, actúa por impulsos y nunca reflexiona. Su objetivo simplemente es divertirse.

Richard también se convierte en Niño cuando ve a su mujer herida. Le dominan los sentimientos, el dolor y el miedo a perderla. No se acuerda de sus hijos en un primer momento, porque teme quedarse solo sin haber ganado el perdón de Susan. En esa circunstancia, su personaje cumple todas las directrices que citó Berne.

Niño espontáneo: Yussef es un niño físicamente, pero actúa como un adulto, ya que le ha tocado una vida muy dura. Sin embargo, cuando ponen en entredicho su calidad como tirador, se convierte en Niño espontáneo. Sólo habla de ser el mejor. Repite en muchas ocasiones que Ahmed no sabe disparar y se enfada cuando no le dejan el rifle. Su objetivo es ser alguien en la familia, porque es el hermano mediando y siente que nadie reconoce sus logros. De hecho, su lenguaje recoge muchas de las siguientes afirmaciones:

"Es divertido; es asombroso (en broma); yo quiero; me da lo mismo; yo voy a conseguir; cuando crezca; mayor; el mayor, mejor; el mejor; muchos superlativos se emplean en situaciones de juego para demostrar que uno es mejor que los demás con el fin de superar el sentimiento de inferioridad" (Valbuena, 2006a: 49).

Niño adaptado: Este yo es quejumbroso, desconfiado, titubeante, murmurador. Es el Santiago de la aduana, que teme ser detenido por la policía y sólo mira por sí mismo. No deja de repetir "me va a querer chingar" y "vaya chingada", en lugar de pensar que detrás lleva dos niños que no son suyos.

De hecho, cuando escapa de la policía en el desierto, no deja de quejarse. Los niños están llorando y a él le molestan. Por eso, aprovecha que ha despistado a la policía y abandona a sus acompañantes:

Santiago: Le dije que no debía traer a los niños.

(Debbie y Mike lloran)

Santiago: Calla a los niños, carajo. ¡Cállalos!

Amelia: Más despacito, por favor. No pasa nada (a los niños) Por favorcito, Santiago, ya párate mi hijito.

Santiago: Pinche, ahí vienen. Vaya chingada, ahí vienen.

Amelia: ¡Párate, mi hijito, por favor!

(Los niños siguen llorando y Santiago se mete por la tierra)

Santiago: Sal, salgan juntos. Sálganse, tía, por Dios. Sálganse ya, por Dios. Vamos, mi hijita, sálganse. Vamos, vamos, sálganse.

(Santiago se va y les deja en medio del desierto)

PADRE CRíTICO: Susan está en este estado desde el comienzo de la película hasta que resulta herida. Es una persona seria y prudente. No le gusta Marruecos y menos que su marido le haya llevado hasta allí para pedirle perdón. Valbuena define este estado con las siguientes características: "Crítico. Severo. Imperioso. Irritado. Condescendiente. Disgustado" (Valbuena, 2006a: 49).

Para acompañar sus palabras, Susan tiene unos gestos muy característicos. Cuando actúa como Padre crítico, apenas habla, guarda muchos silencios y mira fijamente a su marido con gravedad. Cree que ella tiene razón y Richard debe 
pedirle perdón sin ninguna duda: "Lo que cuenta, sobre todo, en las claves verbales, es su carácter arcaico, no crítico, automático. El padre se evita tiempo de reflexión y simplifica su visión de la realidad, dictando cómo le entiende y cómo quiere que se entienda" (Valbuena, 2006a: 49).

En el siguiente diálogo se puede comprobar que Susan actúa como Padre Crítico y Richard como Niño indefenso ante su mujer. El grupo de turistas ha parado en un chiringuito y se disponen a comer. Los dos se miran detenidamente sin decirse nada. Pero ella parece increparle por algo que el espectador aún desconoce:

Susan: Richard, ¿por qué hemos venido aquí?

Richard: ¿Cómo que por qué?

Susan: Sí, ¿qué hacemos aquí?

Richard: Estar solos.

Susan: Tira el hielo.

Richard: Está caliente.

Susan: Pero no sabes con qué agua lo hacen.

(Susan coge los vasos de los dos y tira los hielos enfadada)

Richard: Dios, ¿quieres tranquilizarte? ¿Por qué estás tan tensa?

Susan: Tú eres la razón de mi estrés y de que no pueda relajarme.

Richard: Podrías intentarlo.

Susan: ¿Crees que no lo intento?

Richard: Nunca me lo perdonarás.

Susan: Ya sabes de qué hablo.

Richard: Eh, no quiero discutir.

Susan: Está bien. Avísame cuando desees discutir. Eso si no huyes otra vez.

PADRE PROTECTOR: Richard deja de ser Niño durante algunos momentos, cuando su mujer está enferma y él tiene que ser valiente por los dos. Si no actúa, no mandarán una ambulancia. Además, tiene que consolar a Susan y asume el rol de Padre protector. Eric Berne (2002: 34) definía las funciones de este estado del ego con las siguientes palabras:

"El Padre tiene dos funciones principales. La primera es la de capacitar al individuo para actuar eficazmente, como si fuera el padre de niños reales, fomentando así la supervivencia de la raza humana. Su valor, en este sentido, queda patente en el hecho de que las personas que en la infancia fueron huérfanas parecen tener más problemas para criar a sus hijos que aquellas que, en su adolescencia, no tuvieron un hogar roto. La segunda función es que el Padre hace que muchas respuestas sean automáticas, lo cual ahorra mucho tiempo y energías. Muchas cosas se hacen porque así es como se hacen".

En Babel, Richard cumple la primera función. Acompaña a Susan y le da fuerzas para seguir luchando por su vida. Mientras, ella ha dejado de ser Padre Crítico para convertirse en Niño adaptado. Reconoce que se ha hecho pis encima y se comporta como una niña pequeña desamparada. Así se muestra en esta conversación: 
Susan: Richard, los niños. Si me muero, cuida de los niños, sobre todo de Mike.

Richard: No vas a morir. No puedes morir.

Susan: No vuelvas a dejarnos solos.

Richard: Nunca os dejaré solos.

Susan: Me he meado encima.

Richard: Tranquila.

Susan: No me he podido aguantar. Se me ha escapado. Tengo ganas otra vez.

Richard: Tienes un cacharro por ahí. Un cacharro. ¿Nos dejas un momento a solas?

(Susan hace pis en el cacharro)

Susan: Por favor.

Richard: ¿Así?

Susan: No, me duele. Así, bien.

(Se abrazan y se besan. Susan llora)

Richard: Perdóname, mi amor. Cuando murió Sammy, no... Huía. Tuve miedo.

Susan: Yo también lo tuve.

Richard: Lo sé.

Susan: Fue por mi culpa.

Richard: No, no fue culpa tuya. Me equivoqué. Te quiero muchísimo. Ya no recuerdo su cara.

ADULTO: Berne definía este estado de ego con las siguientes palabras: "El Adulto es necesario para sobrevivir. Procesa los datos y computa las posibilidades esenciales para enfrentarse con eficacia al mundo exterior" (Berne, 2002: 33).

Atendiendo a esta descripción, en la película hay varios Adultos. El primero de ellos es Abdullah, que deja de ser Padre protector. Su hijo Ahmed le ha dicho que Yussef disparó a la turista y observa a Zorah mientras se desnuda. Es entonces cuando deja de lado su faceta paternal y condescendiente, porque tiene miedo de las consecuencias del disparo. Piensa como una persona que puede pasar a ser terrorista:

Abdullah: ¿Por qué lo hicisteis? ¿Por qué lo hicisteis?

(Pega una bofetada a Anwar)

Abdullah: Contestadme.

Yussef: Estábamos probando el fusil.

(Pega una bofetada a Yussef)

Abdullah: ¿Acaso sois idiotas? Matásteis a una mujer (Dirigiéndose a Zorah) ¿Y tú? ¿Te desnudas delante de tu hermano?

Ahmed: Zorah se desnudó muchas veces para que Yussef la vea.

(Dirigiéndose a Yussef) ¿Es verdad? (Dirigiéndose a Zorah) ¿Es verdad o no?

(Pega una bofetada a Zorah) ¿Por qué nos habéis hecho esto? ¿Dónde está el fusil? ¿Dónde está?

Otro Adulto se puede encontrar en el personaje del agente de aduanas. Vio cómo Amelia y Santiago se escapaban y encuentra a la mujer pidiendo ayuda, en medio 
del desierto. Este personaje cumple las características del yo Adulto: "Neutro. Igual. Frío. Despegado" (Valbuena, 2006a: 49). Detiene a Amelia sin titubeos y al principio, no se cree la historia de los niños perdidos:

Amelia: Tengo que volver a por los niños. Los dejé en el desierto.

Policía: ¿Son ilegales?

Amelia: No. Son americanos.

Policía: ¿Cuándo ha cruzado?

Amelia: No he cruzado. Vivo aquí.

Policía: Por favor, ayúdeme a encontrarlos.

Amelia: Quédese aquí. No se mueva.

Policía: Ok.

(El policía habla por radio con la central y detiene a Amelia, que llora)

Amelia: Los niños, por favor. Van a morir. Ayúdeme. Créame, por favor. ¡Están solos!

(La lleva esposada a buscar a los niños. Pero no les encuentran y la meten en una furgoneta llena de ilegales que han intentado cruzar la frontera)

El último Adulto es el cirujano que atiende a Susan cuando, por fin, es trasladada a un hospital en helicóptero. Se muestra absolutamente frío y da indicaciones objetivas sobre el estado de la mujer. Parece inmune a la terrible situación y larga espera que ha sufrido la pareja en la aldea:

Cirujano: Hay que operar a su mujer enseguida.

Richard: ¿Se pondrá bien?

Cirujano: Es probable. Intentaremos salvarle el brazo. Tiene hemorragia interna y aparece algún coágulo. Corremos riesgo de gangrena.

Richard: ¿Se pondrá bien?

Cirujano: Disculpe, señor. (El cirujano se marcha sin decir nada más)

EXCLUSIÓN: En este apartado se encontraría de nuevo el agente de aduanas. Sin embargo, la situación es distinta a la descrita anteriormente. Durante el primer encuentro con Santiago y Amelia, en la misma frontera, se muestra como Padre excluyente. Es frío y es el que da las órdenes y prohibiciones con estas expresiones: "Abra el maletero", "enséñeme el bolso", "no avance hasta que no se lo indique", "no pise el acelerador", "no diga nada", "no tiene que explicarme nada".

CONTAMINACIÓN: La contaminación del Adulto por el Padre es el prejuicio y está presente en el personaje del policía que interroga a Amelia cuando es detenida. Increpa continuamente a la mujer y en sus palabras puede intuirse cierto racismo, porque la invita a abandonar el país inmediatamente:

Policía de inmigración: Es un milagro que hayamos encontrado a esos niños. La verdad, no sé cómo pudo dejarlos solos en el desierto.

Amelia: ¿Cómo están, señor?

Policía de inmigración: Eso ahora no le incumbe. ¿Sabe cuántos niños mueren cada año intentando cruzar esta frontera? 
Amelia: Sí, señor. Crié a esos niños desde que nacieron. Los he criado día y noche. Les he dado desayuno, comida y cena. Juego con ellos. Mike y Debbie son como mis propios hijos.

Policía de inmigración: Pero no son sus hijos, señora. Además, está trabajando en el país de manera ilegal.

Amelia: ¿Qué sabe de mi sobrino Santiago?

Policía de inmigración: No dispongo de esa información. Hemos localizado a su padre en Marruecos. Se enfadó mucho pero no la denunciará.

Amelia: Gracias.

Policía de inmigración: No obstante, el Gobierno de Estados Unidos estima que ha quebrantado la ley y está decidido a deportarla con carácter inmediato.

Amelia: Verá, señor, yo ya llevo aquí dieciséis años. Tengo mis cosas aquí. Tengo una casa rentada. Toda mi vida está aquí, señor.

Policía de inmigración: Eso debió pensarlo antes, señora.

Amelia: Quiero hablar con un abogado.

Policía de inmigración: Si lleva este asunto a juicio, le puedo asegurar que sólo estará prolongando lo inevitable. Le recomiendo que acepte la deportación voluntaria.

(Amelia rompe a llorar)

\section{ANÁLISIS TRANSACCIONAL}

TRANSACCIONES SIMPLES: Dentro de este tipo de transacciones se encuentran los ceremoniales. En Babel hay un buen ejemplo con la boda mexicana del hijo de Amelia. En ese pasaje, Santiago suelta unas gallinas en un terreno cercado. Se trata de un ritual local, previo al banquete de boda. Los niños pequeños tienen que cazar alguna. El primer ejemplar es degollado por Santiago y después de romperle el cuello, suelta al animal para que dé vueltas hasta morir. Debbie y Mike se asustan porque nunca habían visto algo parecido. Son Niños en edad y en estado de ego. En cambio, Santiago es adulto físicamente, pero actúa como Niño en esa escena.

También son transacciones simples los pasatiempos. Aladro los define así: "Su función es programar el tiempo y en muchos casos, rellenar el espacio de transacciones menores dentro de un juego, por ejemplo con participantes secundarios en él o con espectadores del mismo" (Valbuena, 2006a: 103). Para entenderlo, Babel ofrece la reunión de Chieko y sus amigas en el J-Pop. Las adolescentes sordomudas del equipo de voleibol van allí a menudo con el fin de tomar algo, escuchar música, jugar con videojuegos e intentar conocer a chicos. Todas ellas actúan ahí como Niños.

TRANSACCIONES COMPLEMENTARIAS SIMÉTRICAS: Según explica Aladro, "el intercambio más simple es un intercambio de caricias, es decir, la transacción entre dos personas que están en un mismo estado de ego, y que se reconocen presencia mutua" (Valbuena, 2006a: 112). Si se atiende a esta definición, encontramos una transacción complementaria simétrica entre Susan y Richard (Niño - Niño). Ella está herida y él teme que muera. Los dos se comportan como niños y se propinan caricias mutuamente. Ella le ha perdonado y él quiere mostrarle su amor. El 
significado de su interacción es amor e intimidad. Por fin están solos y pueden manifestar lo que sienten.

Del mismo modo se puede encontrar una transacción Padre Crítico - Padre Crítico. Todos los turistas están en la aldea de Anwar. El veterinario ha cosido a Susan y Richard sale fuera un momento. Los compañeros de viaje le increpan, ya que quieren irse y se establece un diálogo de "indignaciones basadas en prejuicios, no en hechos" (Valbuena, 2006a: 112):

Turista 1: ¿Cómo está su esposa?

Richard: Mal, no deja de sangrar.

Turista 2: Tráigala. Tenemos que irnos.

Richard: ¿Dónde? ¿Adónde la llevo?

Turista 2: En una aldea egipcia así degollaron a treinta y dos alemanes.

Podrían hacernos lo mismo.

Anwar: No señor, aquí no.

Turista 2: ¿Y tú qué sabes? Tenemos que irnos de aquí cuanto antes.

Turista 3: Nos tenemos que ir ya. Tenemos que recoger a nuestros hijos.

Richard: No pueden dejarnos.

Turista 4: ¿Por qué tenemos que quedarnos?

Richard: Por si necesitamos el autobús.

Turista 4: Pueden volver a buscarles.

TRANSACCIONES COMPLEMENTARIAS ASIMÉTRICAS: Son las más numerosas en la película. En ellas, los participantes tienen activados distintos estados del ego. El primer ejemplo es Niño - Padre, que se traduce en admiración. En Babel, esta transacción está presente en la conversación telefónica entre Mike y su padre. El pequeño muestra su cariño por el progenitor y se maravilla al poder hablar con él. Mientras, Richard recoge esa estima y toma fuerzas para aguantar la operación de su esposa, que está siendo intervenida en un hospital de Marruecos.

La segunda parte de esa conversación también incluye una transacción Padre Niño. Richard expresa su amor hacia su hijo y esta manifestación de afecto preocupa al niño. Mike se siente desconcertado e intuye que ocurre algo malo al otro extremo del teléfono:

Mike: Hola, papá.

Richard: Hola, Mike ¿Cómo estás?

Mike: Bien, papá. ¿Sabes? Hoy han traido a clase cangrejos ermitaños.

Richard: ¡No me digas!

Mike: Cogí uno con la mano y me mordió. No me hizo sangre, pero...

(Richard rompe a llorar, pero Mike no puede oírle)

Mike: ¿Papá? ¿Te pasa algo?

Richard: No, estoy bien. No pasa nada.

Antes de que Susan sea trasladada al hospital, Anwar ayuda a Richard en todo momento. Ha llevado a los turistas a su aldea y ha ofrecido su casa a la pareja norteamericana. También se ha preocupado de buscar un médico y una ambulancia. Intenta que Richard mantenga la calma y tome las decisiones oportunas para 
mantener a Susan viva. Por ello, se establece entre los dos hombres una transacción Padre - Adulto, cuyo fin principal es el apoyo. De hecho, cuando Susan es recogida por el helicóptero de la Cruz Roja, Richard no para de dar las gracias al marroquí. Es la única persona que le ha apoyado, ya que el resto de los turistas ha huido en el autobús.

La película ofrece otra transacción complementaria asimétrica, esta vez de tipo Adulto - Niño. Se establece entre Yasujiro y su hija, Chieko. El fin de la conversación es el consejo y la enseñanza, ya que el japonés ve que su hija no es la misma que antes. Cuando acaba el partido de voleibol, van juntos en el coche y tienen este diálogo:

Yasujiro: ¿Qué quieres comer?

Chieko: Quedé en verme con mis amigas del equipo en el J-Pop.

Yasujiro: Sí, pero creí que comeríamos juntos.

Chieko: Te digo que voy a ir a comer con mis amigas. Nunca me prestas atención.

(El padre mira desilusionado hacia otra parte)

Chieko: Mi madre siempre me prestaba atención.

Yasujiro: ¿Por qué siempre quieres discutir? Hija, sabes que yo también la echo de menos. Intento hacer todo lo que puedo por ti.

(Llegan al J-Pop)

Yasujiro: No te olvides: tienes dentista a las tres.

(Chieko se muestra enfadada)

Yasujiro: Cuídate.

El último ejemplo es una conversación telefónica Richard y el representante diplomático estadounidense en Marruecos. Actúan como Niño - Adulto respectivamente. El primero pide ayuda, ya que lleva muchas horas esperando una ambulancia y Susan está muy grave. Pero el segundo se muestra frío y objetivo. $\mathrm{Ha}$ recopilado toda la información y busca la solución que le conviene, plantando excusas a su sufrido interlocutor:

Richard: No, necesitamos ayuda ahora, ¿entiendes?

Representante diplomático: (Por teléfono) Hago todo lo que puedo. El Departamento de Estado hace lo que puede, dada la situación. Hay problemas políticos que tenemos que solucionar.

Richard: Me traen sin cuidado los problemas políticos. Necesito ayuda.

Representante diplomático: (Por teléfono) Todo está en sus manos. ¿De acuerdo? No sé qué más hacer. Esas son todas las noticias. La embajada está informada y hace lo que puede.

TRANSACCIÓN CRUZADA: Berne la definía así: "La que siempre causa y ha causado la mayoría de las dificultades sociales en este mundo, ya sea en el matrimonio, en las relaciones sentimentales, en la amistad, o en el trabajo" (Berne, 2002: 37). Precisamente, en Babel, hay una transacción de este tipo y se da en una especie de conversación amorosa. Chieko se siente atraida por el policía que quiere hablar con su padre. Cree que puede llegar a su corazón dándole pena y 
utiliza una transacción cruzada quejumbrosa. Utiliza el suicidio de su madre y dice, a través de sus notas, que ella la vio morir.

\title{
TRANSACCIONES ULTERIORES:
}

\begin{abstract}
"Berne entiende el adjetivo ulterior como lo que implica un motivo oculto. Las transacciones ulteriores son angulares cuando implican tres Estados del Ego, desarrollándose ostensiblemente en el nivel social y ulteriormente en el nivel psicológico" (Valbuena, 2006a: 137)
\end{abstract}

Si se aplica esta definición a la película de González Iñárritu, se puede encontrar una transacción como la citada en el grupo de turistas. Son hipócritas y traicionan a Richard, ya que se llevan el autobús cuando él no puede verles ni alcanzarles. Además, cuando hablan con él, preguntan por su mujer pero extra verbalmente sólo piensan en marcharse de la aldea. Se puede ver a través de estos ejemplos, que muestran el nivel social y el nivel psicológico de algunas frases:

- (Nivel social) Turista 3: ¿Cómo está su mujer?

(Nivel psicológico): Espero que podamos llevarla en el autobús, porque quiero irme de esta maldita aldea en medio del desierto.

- (Nivel social) Turista 2: Se está haciendo de noche. Hay gente que no se encuentra bien. Es peligroso.

(Nivel psicológico): Estoy harto de esperarle, no me encuentro bien y tengo miedo de que estos marroquíes nos hagan algo.

- (Nivel social) Turista 4: Venga con nosotros, véngase con nosotros.

(Nivel psicológico): Venga ya o nos vamos sin usted.

\section{JUEGOS PSICOLÓGICOS}

Los personajes de Babel apenas se comunican. Sin embargo, sus escasas palabras encierran necesidades y objetivos que no quieren transmitir abiertamente; de ahí la incomunicación que quiere mostrar la película. Por ello, recurren a los juegos en algunas ocasiones. Eric Berne los definía así (Berne, 2002: 58):

"Un juego es una serie constante de transacciones complementarias ulteriores, que progresa hacia un fin bien definido y predecible. Desde un punto de vista descriptivo, es una serie recurrente de transacciones, a menudo repetitivas, superficialmente plausibles, que tienen una motivación oculta; o, dicho en términos más coloquiales, una serie de movimientos con trampa o truco".

\section{Juegos que satisfacen las necesidades de reconocimiento y de incidentes:}

“¿Por qué tenía que sucederme esto a mí?”: Chieko emplea su minusvalía para provocar lástima en el agente de policía. Abandona el lenguaje de signos y escribe todo lo que quiere decir en un cuadernillo. Igualmente, adereza su tragedia con otra mayor: el suicidio de su madre. Dice que vio cómo se quitaba la vida y utiliza el victimismo en esta conversación: 
Chieko: (Escribe) Mi padre no tuvo nada que ver en la muerte de mi madre.

Policía: ¿A qué viene esto?

(Chieko escribe)

Policía: Entonces, cuando su madre se tiró por el balcón, ¿su padre dormía?

(Chieko asiente y salen al balcón. Chieko escribe)

Policía: ¿La vio usted saltar?

(Chieko asiente)

Policía: ¿Se lo ha dicho a los otros agentes?

(Chieko asiente)

Policía: ¿Se puede saber qué intenta decirme?

Chieko cumple este patrón a la perfección. Parece que todas las desventuras le han tocado a ella y le encanta mostrar su amargura para inducir pena en el joven que le gusta. No tiene fuerza para enfrentarse a su recuerdo y su minusvalía, aunque tiene un padre que la quiere y espera que vuelva a él.

Sin embargo, al final de la película, Chieko abandona este juego. Se queda desnuda, en el balcón, esperando a su padre. Cuando él llega, ella calla, coge su mano y le abraza. No necesitan decirse nada porque es su forma de expresar que se compromete a madurar y salir adelante.

\section{Juegos que satisfacen las necesidades de seguridad:}

"Sala de audiencia": Este juego consiste en polemizar para ganar el favor del público. Se proyecta la culpa sobre otro con el objetivo de eximirse de toda responsabilidad. En Babel, este juego aparece en un mensaje de la radio que se oye en la aldea marroquí. Como suele ocurrir, los medios de comunicación actúan como un tribunal, emiten juicios y pretenden que los oyentes adopten la misma postura:

Radio marroquí: Hoy, cerca de Nezarín ha ocurrido un accidente en el que una turista americana resultó herida. Las autoridades hablan de un simple intento de robo. Sin embargo, el Gobierno estadounidense lo ha relacionado con el terrorismo. El ministro Hassan Alzah ha declarado que las células terroristas están totalmente desactivadas. Éste es un acto aislado sin más y no puede hacerse un análisis superficial como el que ha hecho Estados Unidos. Lógicamente, este incidente no daña la imagen ni la economía de nuestro país, por lo que todo volverá a la normalidad.

\footnotetext{
"Pata de palo": Chieko, además de emplear el "¿Por qué tenía que sucederme esto a mí?", juega también con su minusvalía. Utiliza su impedimento físico para librarse de una responsabilidad: madurar. Con sus amigas intenta ser una persona normal. Sin embargo, recuerda a su padre y al policía que es sordomuda y por ello no es normal. Incluso, intenta besar a su dentista en plena consulta, con la boca abierta. Él pregunta si está loca y ella pone gesto triste, intentando decir: "Perdóneme, como soy sordomuda, estoy un poco loca y no debe tenerlo en cuenta".
}

\section{Juegos que satisfacen las necesidades de reconocimiento y estructura:}


“Acorralar": El jefe de policía marroquí se encuentra con los niños en un camino de Marruecos. Está buscando a Abdullah y los niños le mienten porque no quieren decir donde viven. El policía se lo cree pero les amenaza, ya que siente que ocultan algo:

Policía: Qué hay, chico. ¿Sabéis dónde vive Abdulah Abdul?

Yussef: (Mintiendo) Sí, yo lo sé. Tienen que pasar esas montañas.

Policía: Nos dijeron que vive allí.

Yussef: Nosotros, con nuestra madre. Abdulah vive al otro lado.

Policía: Escuchadme. Sí mentís, volveré para cortaros las pelotas.

Yussef: Pueden regresar cuando quieran.

Policía: En marcha.

Otro policía utiliza este juego unido al "Ahora ya te tengo". Se trata del agente de aduanas de Estados Unidos. Santiago y Amelia vuelven de la boda y los niños están sentados en la parte de atrás del coche. Al agente no le gusta Santiago desde el principio. Intenta acorralarle con muchas preguntas y le caza cuando menciona el alcohol. Es su manera de confirmar que tenía razón y que el mexicano es culpable:

Agente de aduana 1: Documentación (Santiago le entrega su pasaporte) ¿De dónde vienen?

Santiago: De México.

Agente de aduana 1: ¿De dónde son?

Santiago: De Valle de Guadalupe.

Agente de aduana 1: Valle de Guadalupe. ¿Adónde se dirigen?

Santiago: A San Diego. Les estoy llevando a casa.

Agente de aduana 1: ¿Quiénes son?

Santiago: Mis sobrinos.

Agente de aduana 1: ¿Sobrinos? No se parecen a usted, señora.

Amelia: No, no, no. Cuido de ellos. Soy su ama.

Agente de aduana 1: ¿Tiene sus pasaportes?

Amelia: Sí (Amelia entrega los pasaportes de los niños)

Santiago: ¿Algún problema?

Agente de aduana 1: ¿Debería haberlo? (Santiago niega con la cabeza)

Agente de aduana 1: Esperen un momento (El policía se va hacia la caseta de la aduana)

Santiago: (A Amelia) No diga nada, ¿eh?

Amelia: Ay, hijo.

Santiago: Nada.

(Un segundo policía vuelve con una linterna)

Agente de aduana 2: ¿Puede abrir su maletero, señor?

Santiago: ¿Qué?

Agente de aduana 2: Abra el maletero.

Santiago: Sí, sí, sí.

(El policía rebusca en el maletero)

Agente de aduana 2: Ciérrelo. Vuelva al coche. Abra la guantera, señora. ¿El bolso? (Amelia se lo entrega y el agente lo observa detenidamente) Bien.

(Vuelve el primer agente)

Agente de aduana 1: Señora, ¿está usted a cargo de ellos?

Amelia: Sí. 
Agente de aduana 1: Necesitamos el consentimiento paterno.

Santiago: ¿Qué es eso?

Agente de aduana 1: Una autorización del padre (Dirigiéndose a Debbie, que se acaba de despertar) Hola, guapa. ¿Esta señora es tu tía?

Debbie: No, no es mi tía.

Santiago: No, cuida de ellos.

Agente de aduana 1: ¿Ha bebido usted?

Santiago: ¿Yo?

Agente de aduana 1: ¿Está bajo los efectos de alcohol?

Santiago: No.

Agente de aduana 1: Bien, lo comprobaremos. Salga del vehículo. Le he dicho que salga del vehículo (El policía pone su mano sobre la pistola).

Santiago: Oiga señor, puedo explicarle.

Agente de aduana 1: No tiene que explicarme nada. Obedezca. Le he dicho que salga del vehículo. Espere. Ponga la marcha y vaya al área de inspección.

Santiago: No me grite, no me grite. ¡Más no me grite!

Agente de aduana 1: Calle y haga lo que estoy diciendo.

Santiago: ¡Mas no me grite!

Agente de aduana 1: Aparque a la derecha su vehículo.

\section{BIBLIOGRAFÍA}

Berne, E. (2007): Juegos en que participamos. Barcelona: RBA Integral.

Cantor, M.G. (1981). Prime-time television. Content and control. Londres: Sage Publications.

Forero, M.T. (2002). Escribir televisión. Manual para guionistas. Barcelona: Paidós.

Kelsey, G. (2003). Escribir para la televisión. Barcelona: Paidós.

López, N. (2008). Manual de guionista de comedias televisivas. Madrid: T\&B Editores.

Lumet, S. (2004). Así se hacen las películas. Madrid: Rialp.

Nash, C. y Oakey, V. (1978). The television writer's handbook. What to write, how to write it, where to sell it. Nueva York: Barnes \& Noble Books.

Sussman, S. (1995). Así se crean programas de televisión. Cómo se hacen reportajes, series, concursos y anuncios. La creación televisiva. Guiones, producción, cámara, grabación y edición. Barcelona: Editorial Rosaljai.

Valbuena, F. (2006a): Eric Berne. Teórico de la Comunicación. Madrid: Edipo.

Valbuena, F. (2006b). Análisis de la película Esencia de mujer (1992), en Revista de Análisis Transaccional y Psicología Humanista, no 60, p. 17-21. 
Valbuena, F. (2007a). Análisis de la película Hotel Rwanda (2004), en Revista de Análisis Transaccional y Psicología Humanista, no 61, p. 71-79.

Valbuena, F. (2007b). Análisis de la película La vida de los otros (Desde el Análisis Transaccional y la Teoría de la Negociación), en Cuadernos de Información y Comunicación, ํo 12, p. 119-135. 